\title{
PERCEIVED CSR AUTHENTICITY
}

Sarah Alhouti, University of Alabama, USA

Betsy Holloway, Samford University, USA

Catherine Johnson, University of Alabama, USA

\begin{abstract}
Marketing literature shows that while consumers often respond positively to corporate social responsibility (CSR) initiatives (Bhattacharya and Sen, 2004) they are also known to be skeptical of corporate social responsibility (Webb and Mohr, 1998). This paper argues that these contradictory and changing consumer attitudes towards CSR may be attributable to consumers' perceptions as to the authenticity of a company's CSR. While it is intuitive that inauthentic CSR would create a negative consumer evaluation of a company (Wagner, Lutz, and Weitz, 2009), this paper contributes to the literature in that it seeks to uncover what, exactly, it is that influences the perceived authenticity of CSR initiatives. To begin to understand the thought processes behind consumer's evaluations of CSR, a qualitative analysis of interviews was undertaken. Initial findings suggest that consumers' perceptions of what makes CSR authentic or not can be fall into several broad categories including how well a CSR initiative fits the company, firm reputation, and whether or not the firm seems to be motivated by profit instead of altruism.
\end{abstract}

References available upon request. 